\title{
An Empirical Investigation of Factors Determining Actual Usage of Entertainment Streaming Apps in India
}

\author{
Vishal Kulshrestha, Amity International Business School, Amity University, Noida, India \\ Kokil Jain, Amity University, Noida, India \\ Isha Sharma, School of Administrative Studies, York University, Canada * \\ (iD) https://orcid.org/0000-0002-5332-3642
}

\begin{abstract}
The rise of internet and penetration of smartphones have made digital content accessible through entertainment streaming apps (ESA). With the flexibility of time and place, ESA platforms are changing the dynamics of entertainment consumption. The current study explored the determinants of actual usage of ESA using the theory of planned behavior, flow theory, and factors affecting entertainment-related technology adoption including engagement, content, entertainment value, convenience value, and monetary value. Data is collected through an online survey from 215 Indian ESA users, and the proposed framework is empirically tested using partial least squares structural equation modeling (PLS-SEM). The findings of the study contribute to the growing body of literature on streaming apps adoption and usage by expanding the understanding of the factors that explain their usage behavior.
\end{abstract}

\section{KEYWORDS}

Actual Usage, Engagement, Entertainment Streaming Apps, Flow Theory, Theory of Planned Behavior

\section{INTRODUCTION}

A 35-years old, Delhi based engineer, much like, a 25-years old freelance musician in Mumbai, ceased to watch television (TV) sometime back. It is because they do not prefer being held up at a specific time to watch a show. Internet has given them the opportunity of watching the content of their choice at their own convenience through Entertainment Streaming Apps (ESAs). They binge watch their favorite shows and movies on different platforms offering access to digital content available globally.

ESAs refer to the delivery of music or video services through internet mediated platforms. These services include video content, movies, serialized TV shows or music. The unique aspect of these platforms is that they enable their users to watch their preferred content at any place or time (Oyedele \& Simpson, 2017) which makes these applications a preferred mode of digital media consumption. Various factors, including the increase in smartphone penetration and unlimited data connectivity at affordable prices has fueled the growth of streaming apps. Moreover, changes in lifestyle, and 
consumers' need for entertainment, anywhere, any time and any device (AWATAD) have been crucial for the rise of these platforms (Medina, Herrero-Subias, \& Guerrero, 2015; Gimpel, 2015).

The emergence of live streaming apps has heralded a new era of entertainment consumption in India, where ESAs operate on two revenue models: advertisement based and subscription based. The affordable subscription rates of Netflix, Amazon Prime and Hotstar (the three major ESA service provider in India) has caused traditional television screens to lose their monopoly over digital content. With the growing preference for over-the-top (OTT) viewing and video-on-demand (VOD), ESA users are increasingly ditching television. Evidently, ESA are convenient and economical alternative to other sources of entertainment; while some users may also be driven purely by its entertainment value offered by the digital content available on these apps.

According to the recent 2019 Internet Trends Report, India has the second largest internet user base in the world, consisting of $12 \%$ of the global internet users (The Quint, 2019). This has been facilitated by the launch of Reliance Jio in India in 2016 that offered unlimited access to fourthgeneration $(4 \mathrm{G})$ data and voice services to its subscribes at affordable rates. There has been a steep rise in the digital media consumption in India since the launch of Reliance Jio. As per Indian OTT Platforms Report, (2019), there has been an increase of 140\% in the time spent on streaming apps across India, Australia, Indonesia, South Korea and Thailand. This indicates the changing consumer behavior regarding digital entertainment consumption. The online video market in India is estimated to be worth USD 4 billion by 2025 , with $1 / 3^{\text {rd }}$ of the revenue to be contributed by subscription based apps and the remaining to be accounted by advertising (Jha, 2020). The phenomenal success of ESAs has attracted other broadcast channels including Disney and HBO to adapt their business models and join the row of existing streaming giants.

Despite the enthusiasm surrounding this sector, scholarly research in this domain remains limited. Majority of the existing studies have used the context of live streaming usage intentions rather than ESAs in particular. The focus of these studies is divided across social live streaming services (Chen \& Lin, 2018, Hilvert-Bruce, Neill, SjÖblom \& Hamari, 2018), online videos game streaming (SjÖblom \& Hamari, 2017), video or music entertainment streaming apps (Oyedele \& Simpson' 2017; Hu, Zhang, \& Wang, 2017; Kinnally \& Bolduc, 2020); and more recently live streaming of sports (Kim $\&$ Kim 2020). While these studies significantly contribute to the growing body of literature on live streaming usage behavior, it is essential to examine whether the findings of these studies can be extended and validated, specifically in the context of subscription based video streaming apps. The widespread popularity of ESAs and the paucity of research in the area presses the need for further investigation that explores the determinants of ESA usage.

Against this background, the objective of the current study is to discern the factors governing the viewers' actual usage behavior in the context of subscription based video entertainment streaming apps. Using, the theory of planned behavior (TPB) (Ajzen, 1991), and flow theory (Csikszentmihalyi, 1975) as overarching theories, a framework is proposed that integrates the predictors of entertainment related technology adoption variables such as content and engagement and perceived value dimensions such as entertainment value, convenience value, monetary value that together explains the existing subscribers' actual usage behavior. The TPB provides a suitable framework for understanding how various social and attitudinal factors influence our behavior (Ajzen \& Fishbein, 1988). The theory has been applied to a variety of technology and media adoption studies (Kinnally \& Brinkerhoff, 2013) including streaming services (Kinnally \& Bolduc, 2020). Similarly, flow theory is suitable for assessing viewer behavior in the context of ESAs as it explains how people feel when they are totally absorbed in an activity. Flow experience has been previously applied in the context of online gaming (Liu, 2017; Su, Chiang, Lee \& Chang, 2016; Ari, Y1lmaz, \& Dikec 2020) and sports media consumptions (Kim \& Ko, 2019). Considering that ESAs incite binge-watching behavior (Merikivi, Bragge, Scornavacca, \& Verhagen, 2019), flow experience can significantly explain ESA usage.

The findings of the study are expected to raise pertinent managerial implications in light of the growing competition in the ESA market, since established as well as emerging platforms fight to 
maximize their respective screen time. The focus of this study is to understand actual usage (measured by the time spent on streaming content) and not just behavioral intention. By identifying factors that drive the actual consumption of ESAs, the results can aid marketers and streaming app developers to build an engaging viewership.

The forthcoming section provides a brief background on the rise of ESAs and discusses the most relevant scholarly contributions in this domain. Thereafter, argument for development of hypotheses are provided followed by method and discussion of results. Towards the end, key implications of the findings are elaborated upon. Finally, the limitations of the study and future scope of work is discussed.

\section{THEORETICAL BACKGROUND AND REVIEW OF LITERATURE}

\subsection{Rise of Entertainment Streaming Apps (ESAs)}

Although streaming services are considered to be a recent phenomenon, digital video viewing goes back to 1970s, when Sony Corp. promoted, the short-lived, Betamax VCR (Greenberg, 2010; Bury \& $\mathrm{Li}, 2013$ ). Subsequently, the rise of digital video recording (DVR) in the US market initiated the trend of digital consumption in late 90's. However, the real evolution of media consumption through digital formats can be attributed to the breakthrough of computer technologies. Following the commencement of the World Wide Web, a multitude of video streaming and downloading services emerged like iTuns, Realplayer and Quick Time (Chen, 2019). This also led to a debate on copyrights (Schiesel, 2004) and charging reasonable royalties became a matter of concern within the media industry. YouTube traversed through different phases since 2000, from streaming of short small budget programs and plays to eventually streaming of full TV shows or online programs (Steinkamp, 2010; Chen, 2019). Gradually, subscription based business model emerged and broadcasters and production houses begun to identify the strategic importance of streaming TV shows or original content specially meant for online platforms. In 2013, Netflix decided to invest millions of dollars to stream all episodes of House of Cards together after it failed to land up with a contract to stream HBO content. Little did anyone know, the streaming giant's bold step is going to bring an industry breakthrough that would change the consumer's entertainment consumption preferences by giving rise to the era of Binge Watching.

The rise in the number of devices that support digital media along with unlimited access to internet has also facilitated the consumers to access entertainment anytime, anywhere. The devices used to access digital content have shown unprecedented growth serving as a catalyst to the rise of an array of online streaming app platforms. According to a KPMG report, the number of videocapable devices and connections are expected to be doubled by 2021 (The Quint, 2018). With India projected to be one of the fastest growing market for ESAs, close to 36 streaming platforms have been launched, most of which operate on subscription or hybrid (advertisement + subscription) based revenue model. The penetration of global ESA platforms challenged the paid TV providers and broadcasters. This compelled them to offer TV to their viewers everywhere. This explains the entry of local channels and broadcasters (Sony launched SonyLIV and ZEE launched ZEE5) in the ESA market. The lockdown imposed in light of the Covid-19 situation further helped OTT platforms to secure more subscribers. Reports indicated a rise of $8-100 \%$ in subscription of major OTT platforms (The Economic Times, 2020). Globally too, video streaming services experienced a rise in viewership by 10\% during Covid-19 lockdown (Market Analysis Report, 2020).

\subsection{Factors Influencing Streaming Behavior}

Other than the groundbreaking revolution in technology, rise of internet and smartphone, there are to be multiple factors, specific to streaming sites and its users that would drive the success of streaming apps. A stream of research focusing on social live streaming services (SLSS) and video on demand (VOD) has emerged in the recent years that has identified various factors that have contributed to the rapid adoption of streaming apps including live streaming videos, music and videos sharing. Most 
recently, Kim and Kim (2020) posited that flow and satisfaction of watching sports online is driven by gratification expectation (cognitive, affective, personal and social integration and tension release). They assert that watching live stream sports can enhance users' social well-being and alleviate loneliness. These findings are also replicated in the study by SjÖblom and Hamari, (2017) in the context of video game streaming, who found that gratification needs can influence the number of hours that people spend on watching game streams. In the context of over the top (OTT) entertainment platforms, Chen (2019) provided evidence that convenience influences users' gratification with OTT entertainment and makes them a preferred choice over cable television.

Earlier, Chen and Lin (2018) examined factors influencing individual's live-streaming usage intention on social networks. Drawing perspectives from flow theory, entertainment and social interaction, their study suggested that people watch live-stream videos to feel happy and relieve stress. Streamer characteristic also influenced their intention to watch these videos on social media. Oyedele and Simpson (2018) found that consumption values offered by streaming apps (convenience, emotional and social value), cognitive effort and identity salience are the crucial predictors of their usage and recommendation intentions. Hilvert-Bruce et al. (2018) identified six motivators based on uses and gratification theory that significantly predict live-stream viewers' engagement on Twitch, indicated by their emotional connectedness, time spent, time subscribed and donations made. In case of video sharing sites like YouTube, prior studies suggest that sharing behavior and continuance motivation are important factors affecting platform stickiness and mediate the effect of need, personal, and environmental factors (Chiang \& Hsiao, 2015). While this extant literature sheds light on the digital media consumption behavior in varied contexts, there remains a paucity of research examining the factors affecting actual usage of subscription based ESAs.

\section{HYPOTHESES DEVELOPMENT}

\subsection{Effect of Flow Experience on Engagement and ESA's Actual Usage}

Defined as a mental state in which one gets extremely involved and absorbed in an ongoing activity, the concept of flow was first proposed by Csikszentmihalyi (1975). According to the theory, flow experience leads to complete engagement in an activity, characterized by concentration and enjoyment (Ghani \& Deshpande, 1994). Flow experience has been previously studied in the context of online games (Su et al., 2019; Sanjamsai \& Phukao, 2018), social media platforms (Hung, Tsai \& Chou, 2016) and instant messaging services (Lu, Zhou, \& Wang, 2009), indicating that flow experience may be associated with attitude and thereby the intention to use particular system (Hung et al., 2016; Chen $\&$ Lin, 2018). Sanjamsai and Phukao (2018), discusses flow as an optimal state where the person is fully immersed in an activity.

ESAs are popularly known for releasing all episodes of a season, that the viewer can stream in one go. This trend, started by Netflix's famous show, House of Cards, is now commonly referred to as Binge Watching behavior (Merikivi et al., 2019). This particular characteristic that allows users to continuously binge watch content on ESAs creates an immersive viewer experience that can be attributed to flow experience. Hoffman and Novak (2009) have argued that flow experience can influence user intentions (Ari et al., 2020), loyalty (Su et al., 2016), positive affect (Rogatko, 2009), engagement (Högberg, Ramberg, Gustafsson, \& Wästlund, 2019) and even attitude (Hsu \& Lu, 2004). Overall, the aforementioned assertions support that enhancing the viewers' flow experience can increase their engagement as well as actual usage of ESAs.

H1a: Flow experience is positively associated with engagement

H1b: Flow experience is positively associated with actual usage of ESA 


\subsection{Determinants of Flow Experience}

According Hoffman and Novak, (2009), people must be influenced by a certain antecedent that causes them to experience a state of flow. They asserted that flow has a hierarchical composition, constituting of its antecedents, flow and outcomes. Earlier, studies suggested that flow experience depended on perceived enjoyment, perceived control (Lu, et al., 2002; Zaman, Anandarajan \& Dai 2010), concentration (Ha, Yoon, \& Choi, 2007), and attention focus (Zhou \& Lu, 2011).

ESA are specifically meant to offer entertainment and enjoyment to its users. These apps deliver digital content including movies, videos, music, TV shows to its users, who may consider entertainment to be one of the most valuable attributes of ESA. Entertainment draws people's interest and attention, makes them feel happy and relaxed by providing a diversion from their daily routine life (Chen \& Lin, 2018). Prior studies have asserted that media is considered as a source of entertainment and relieving stress (McQuail, 2010). From a hedonic perspective, consumers desire pleasure, fun and entertainment from the use of a product or a service. Entertainment value is exhibited in leisure activities (Tseng, Huang \& Setiawan, 2017), including watching movies or TV shows or playing a game and even participating in events (Madupu \& Cooley, 2010). People who seek entertainment are not driven by any specific objective but to pass the time (Tseng et al., 2017).

Prior studies have correlated entertainment with smartphone addiction (Kim, Kim \& Wachter, 2013) and loyalty to a particular website (Kim \& Niehm, 2009) suggesting that its influence on continued behavior. Website interestingness has been known to induce flow (Hsu, Chang \& Chen, 2012). Recently, Chen and Lin (2018) also asserted entertainment positively impact flow when watching a live stream. Therefore, the current study proposes:

H2: Entertainment value is positively associated with flow experience

\subsection{Theory of Planned Behavior: Determinants of Attitude}

\subsubsection{Engagement}

Researchers have vastly explored engagement with respect to media content. Engagement is used to account for the motivational experiences of consumers, arising out of their interaction with a particular media (Kim et al., 2013; Wu, 2016; Calder \& Malthouse 2008). Bellman, Potter, Treleaven-Hassard, Robinson, and Varan (2011) assert that consumers are likely to possess positive responses towards brand that offer more engaging mobile apps. Prior studies have correlated engagement with perceived value of mobile social networks (Wu, 2016); online experiences of consumers (Mollen and Wilson, 2010); as well as attitude towards media content (Bardzell, Bardzell, Pace, \& Karnell, 2008; Sundar, 2007;). Kim et al. (2013) studied engagement with respect to branded mobile apps and affirmed that mobile app engagement with branded apps leads to positive brand evaluations and thereby stronger relationship. More recently, Hilvert-Bruce, et al., (2018) studied the social motivation factors predicting user engagement in live streaming multimedia platform named Twitch.

Unlike the family-oriented content on TV, ESA offer personalized content made for its users who can consume it on devices with time and place of their choice. ESA platforms are creating content that Indian television never did thereby creating stronger appeal and influence among their viewers. This is not restricted to shows and movies produced in the west. Sacred Games, India's first original series on Netflix, was well received by the global audience. Amazon Prime's critically acclaimed series Made in Heaven also broke the traditional format of content offered by Indian soap operas, that was often limited in creative expression. This format of content is high on engagement and hooked the audience through their unique and binge-worthy appeal (Sundaravel \& Elangovan, 2020). Taking lead from the success of this format, emerging platforms have also joined the race for produce content which is high on engagement and that can fuel Indian audiences' interests even further. 
Though engagement, as a predecessor to usage behavior, has been widely studied in the context of interactive and online media, it is yet to be investigated with respect to ESA usage and its evaluation. The study asserts:

H3: Engagement is positively associated with attitude towards ESA

\subsubsection{Content}

In their study on web sites success, De Wulf, Neill, Sjöblom, \& Hamari (2006) indicated that content of a website is concerned with "believability, timeliness, applicability, and the amount of information provided by the web site" (P.435). Their study confirmed the positive association between website content and commitment - an attitudinal outcome. ESA are part of a trend where digital content is delivered through computer mediated networks such as the internet. In contrast to the traditional media, ESA users are actively involved with the platform, as it is more interactive and personalized in nature (Feijoo, Maghiros, Abadie, \& Gómez-Barroso, 2009; Lai \& Turban, 2008). These apps serve as independent mediums with diversified and customized content.

Prior studies on website engagement have supported that interactivity of a portal draws user attention to web content and increases their engagement (Sundar, 2012). This kind of involvement may affect the way the users evaluate the value of the content offered by ESA (Feijoo et al., 2009; Hargittai \& Walejko, 2008; Lai \& Turban, 2008). Consumers prefer mobile apps when in-app content meets their needs and preferences (Kim \& Baek, 2018). ESAs rely on creativity to generate content that can grow subscriptions. Content offered by ESA is not only flexible and customizable but also fulfills the users' need for time utility and relevance, which in turn should lead to a favorable evaluation of ESA. Therefore, it is hypothesized

H4: Content is positively associated with attitude towards ESA

\subsubsection{Convenience Value}

Over the top (OTT) platforms inarguably rate highest in the convenience dimension (Chen, 2019). Easy to access content, flexibility of time and place characterizes the convenience offered by ESA which makes them preferable digital consumption medium over traditional television. Prior research has found the relevance of convenience value in determining consumers' attitude towards and intention to use mobile and other technologies (Collier, Sherrell, Babakus, \& Horky, 2014; Pura, 2005; Pihlström \& Brush, 2008). Recently, Oyedele and Simpson (2018) positively correlated perceived convenience value and streaming apps usage rate. Previously, convenience value has been found to positively influence intention to recommend and use online apparel shopping (Hongyoun Hahn \& Kim, 2009) and online banking services (Loureiro, Kaufmann, \& Rabino, 2014). Additionally, time convenience has been studied with respect to mobile app technology (Zhao \& Balagué, 2015, Kim \& Baek, 2018). Kleijnen, De Ruyter \& Wetzels (2007) also posited that time convenience leads to an increased overall assessment of the functionality of mobile channel usage. Consistent with prior research, the current study proposes the following hypotheses:

H5: Convenience Value is positively associated with attitude towards ESA

\subsubsection{Monetary Value}

In addition to the huge library of content, ease of use, consumers may find value in ESA for its perceived monetary value. Subscribing to even multiple different streaming apps can be a cheaper alternative to cable TV subscriptions in India that costs around INR 5000 per annum (on average for HD channels). Whereas, Amazon Prime and Hotstar both charge INR 999 per year. Although 
the monthly subscription of Netflix is more expensive, the company recently launched a cheaper alternative of subscribing to Netflix mobile at INR 199 per month. These are the three major ESA players in India and subscribing to all of them together can be cost less than annual HD cable TV subscriptions. All these ESA players also provide the initial one-month subscription free with the aim of enhancing consumers' perception of monetary value.

Defined by Venkatesh, Thong \& Xu (2012) as a consumer's conscious trade-off between using a system and perceived benefit derived from it, monetary value plays a crucial role within the context of consumer technology use, as the user has to bear the costs associated with the use of the system. In line with this thought, many studies on consumer behavior have included variables related to price in order to understand consumers' actions. For instance, the cost of using mobile banking services influences the consumer's intention to adopt it (Hanafizadeh, Behboudi, Koshksaray, \& Tabar, 2014). Oyedele and Simpson (2017) found positive influence of perceived monetary value on streaming app usage as well as recommendation likelihood. Studies on e-commerce websites have asserted similar relationships (Luo, Ma, Lin \& Gan, 2011). Therefore, it can be asserted that monetary value shall be important in determining an individual's attitude towards using streaming apps.

H6: Monetary Value is positively associated with attitude towards ESA

\subsection{Theory of Planned Behavior (TPB): Role of Attitude, Subjective Norms and Perceived Behavioral Control}

According to Ajzen (2002), the TPB helps explain the behavior of individuals, when there is no intrinsic control over the behavior. An extension of the theory of reasoned action, TPB states that the prediction of intention depends on attitude, subjective norms and perceived behavioral control; intention to perform a specific task further determines the likelihood of actual execution of that behavior. The TPB has been widely used in information system (IS) research, including online gaming (Alzahrani et al., 2016), user engagement in virtual world (Mäntymäki et al., 2014), mobile shopping adoption (Yang, 2012), e-service continuance (Liao, Chen \& Yen, 2007), information and communication technology use continuance (Kaba, 2018). The theory has been earlier expanded TPB to predict music streaming behavior and usage (Lin, Hsu, \& Chen, 2013; Boldun \& Kinnally, 2018; Kinnally \& Bolduc, 2020). Like any other behavior related to technology and media consumption, ESA viewer behavior can be argued to be a complex interplay of technical, social, economic and psychological factors. The current study therefore finds the TPB a suitable framework to examine the factors of ESA usage among its users.

\subsubsection{Attitude}

Attitude is an individual's favorable or unfavorable assessment of a particular object in question (Fishbein \& Ajzen, 1975; Simons, 1976). Prior studies on information systems research have found positive association between attitude and adoption behavior, for example in the context of smartwatch usage (Kim \& Shin, 2015) and user engagement in the virtual world (Mäntymäki et al., 2014). Moreover, a series of research on music streaming indicates that a positive attitude towards streaming services can influence the likelihood of music streaming usage (Delikan, 2010; Dörr, Wagner, Benlian, \& Hess, 2013; Kinnally \& Bolduc, 2020). Thus it can be asserted that attitude towards ESAs, should also determine its usage.

H7: Attitude is positively associated with Actual Usage of ESAs

\subsubsection{Subjective Norms}

Subjective norms account for the role of social influence in an individual's behavior. They are normative beliefs held by an individual about social expectations. It is indicated by the theory of 
planned behavior that behavioral intention is an outcome of one's desire to follow referent group norms, which can be reflected in the effect of subjective norms. Extant literature on technology acceptance and adoption has supported the role of subjective norms in driving specific behavior. Chang, Liu and Chen (2014) found that subjective norms significantly determine online game playing. Alzahrani, et al (2016) correlated subjective norms with actual online game playing behavior. Yang (2013) found subjective norms as predictor of mobile apps attitude. Chiang and Hsiao (2015) found that social norms positively influence sharing behavior on YouTube.

The role of normative influences is especially relevant in the context of ESAs since most of these platforms social interaction with other people in one's network. Subscribers can share and recommending content with one's social network. Therefore, it can be argued that an individual's immediate reference group can influence their ESA usage behavior.

H8: Subjective norms is positively associated with Actual Usage of ESA

\subsubsection{Perceived Behavioral Control}

Perceived behavioral (PBC) control refers to one's perception of the available skill, resource and opportunity required to perform a certain behavior. Behavior depends on both situational constraints and facilitating conditions, which may encourage or discourage the intention to perform a behavior. Ajzen (2002) ascertains that PBC includes both internal and external control factors. The former is under individual control and shall include skills, power, etc. The external factors are not within the control of an individual and refer to opportunities or cooperation of others. It was Compeau and Monroe, (1995) who applied PBC in the context of the information technology (IT) research and defined it as the individuals' reliance on their potential and skill to use an ICT. This implies that an individual may deny using a particular system because of lack of skills required to use it effectively. In using ESA, the users must have basic knowledge of the internet or mobile apps; they need to have smart phones and occasionally must register with the service provider. Someone who is not well versed with the knowhow of smartphone and mobile app usage might find it challenging to use ESA, therefore it is proposed:

H9: Perceived behavioral control is positively associated with actual usage of ESA

Figure 1 represents the research model that is proposed based on the hypothesized relationships:

\section{METHODOLOGY}

\subsection{Data Collection}

Data on the proposed constructs was collected through an online structured questionnaire among ESA users located in the National Capital Region of Delhi in India. Snowball sampling technique was used to identify respondents, who currently held subscription for at least one ESA platform. Additionally, social media was used to identify potential respondents. Data were collected from a total of 235 respondents. After eliminating incomplete and unengaged data, a total of 215 responses were used for the analysis.

Out of the total respondents, 144 were females and 69 were male. 14 respondents were less than 18 years of age, 121 respondents were within the age group of $18-24$ years, 46 were between $24-30,19$ were between $30-40$ and 10 were above the age of 40 years. More than $50 \%$ (163) of the respondents held subscriptions for multiple platforms together. All the respondents reported to hold subscription for either one of the three most popular streaming apps: Netflix, Amazon Prime and Hotstar. 


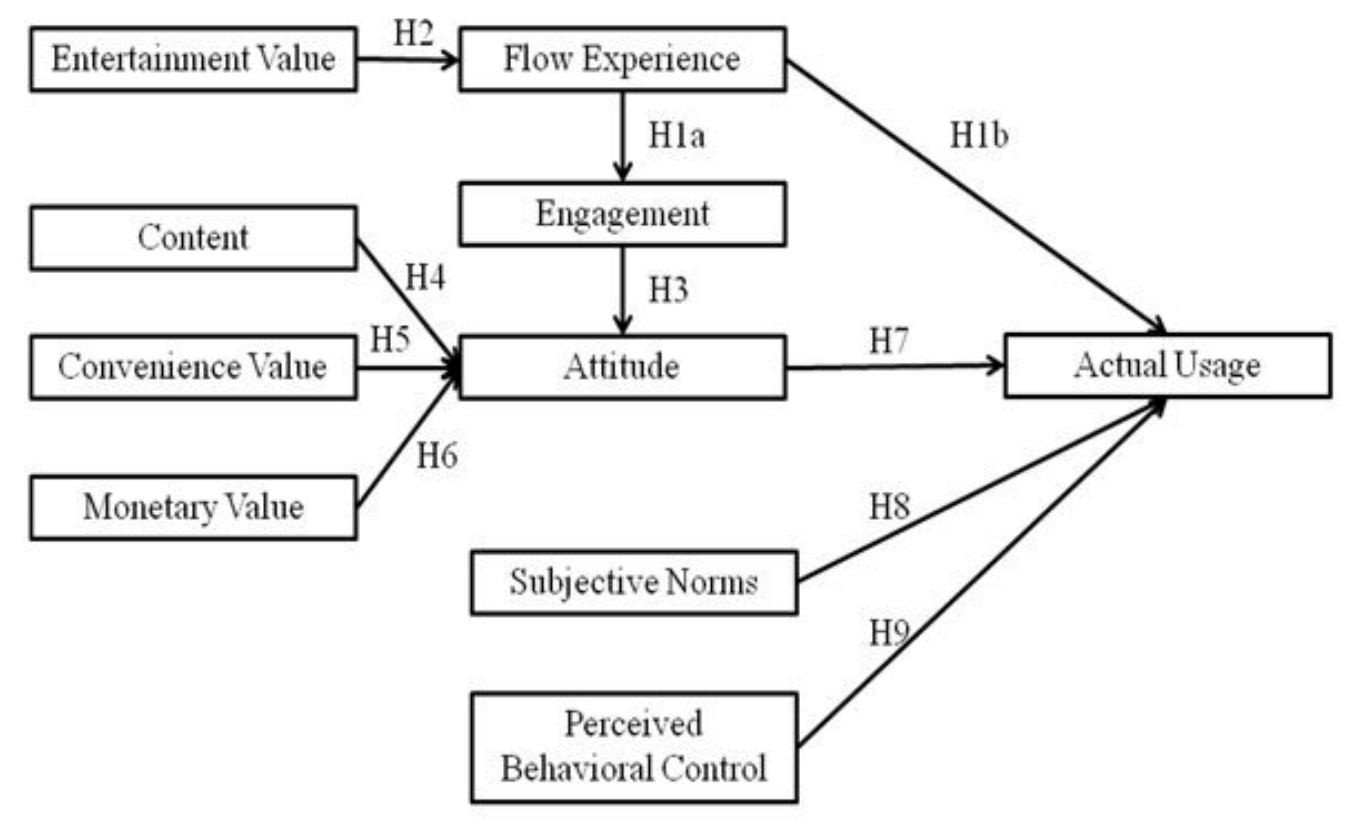

\subsection{Measurement Instrument}

The measurement instrument was constructed using previously established scales for measuring the constructs. The survey began with recording basic demographic information (age, gender, professional status and income group). This was followed by questions asking respondents to indicate the ESA platforms that they are currently subscribed to. Thereafter, responses were recorded for the statements reflecting the respective constructs in the theoretical model. Convenience value was adapted from the 5 item scale by Collier et al. (2014). Content was measured using the 3 item scale by De Wulf et al. (2006). The scale for entertainment value was taken from the 4 item scale by Venkatesh et al., (2012). The five items scale for flow experience was adapted from Lu et al., (2009), while the three item scale for engagement was taken from Ghani and Deshpande (1994). Monetary value was measured using 3 item scale by Mohd-Any, Winklhofer, and Ennew (2015). For attitude, 5 item bi polar scale, proposed by Ajzen (2002) was used. Both 3 item scale for subjective norms and 4 items for perceived behavioral control were adapted from Ajzen (1991). All the items were measured on a 5 point likert scale anchored from $1=$ strongly disagree to $5=$ strongly agree. Actual usage of ESA was measured by asking the respondents to report the average number of hours they spent per day, watching content on ESA. This method to measure actual usage has previously been used by Oyedele and Simpson (2017) and Alzahrani et al. (2016). The scale items used to measure the constructs of the research model are summarized in the Appendix.

\section{RESULTS AND ANALYSIS}

The study used partial least squares structural equation modeling (PLS-SEM) with SmartPLS v.3.2.7, to test the measurement and structural models. PLS-SEM is considered suitable for the analysis as 
Table 1. Construct Reliability and Validity

\begin{tabular}{|l|l|l|l|l|}
\hline & \multicolumn{1}{|c|}{ Cronbach's Alpha } & \multicolumn{1}{c|}{ rho_A } & \multicolumn{1}{c|}{ CR } & \multicolumn{1}{c|}{ AVE } \\
\hline ACTUAL_USAGE & 1 & 1 & 1 & 1 \\
\hline Attitude & 0.895 & 0.901 & 0.894 & 0.63 \\
\hline Content & 0.755 & 0.784 & 0.752 & 0.513 \\
\hline Convenience Value & 0.82 & 0.819 & 0.817 & 0.472 \\
\hline Engagement & 0.855 & 0.857 & 0.855 & 0.663 \\
\hline Entertainment Value & 0.815 & 0.842 & 0.824 & 0.545 \\
\hline Flow Experience & 0.81 & 0.812 & 0.806 & 0.511 \\
\hline Monetary Value & 0.887 & 0.889 & 0.885 & 0.721 \\
\hline Perceived Behavioral Control & 0.835 & 0.838 & 0.835 & 0.56 \\
\hline Subjective Norms & 0.752 & 0.759 & 0.755 & 0.508 \\
\hline
\end{tabular}

the study contains a single item construct (actual usage) along with reflective measures (Hair, Ringle, \& Sarstedt, 2011).

The data was first tested for common method variance using the process suggested by Kock (2015), who recommends a full collinearity test in PLS-SEM. According to this method, variance inflation factors (VIF) were generated for all latent variables in a model. The inner VIF values of all the constructs in the proposed model were below the recommended value of 3.3 (Kock, 2015), indicating the model to be free of common method bias.

\subsection{Assessment of the Measurement Model}

All the measurement items were tested for internal consistency, convergent validity and discriminant validity. Convergent validity in the model was assessed using factor loadings, average variance explained and composite reliability based on the process suggested by Hair et al. (2011). The factor loadings (Appendix) of all the items on their respective constructs were above the recommended threshold of 0.5 (Hair et al., 2011). Cronbach's alpha and composite reliability for all the items were above the recommended value of 0.70 (Hair et al., 2011; Henseler, Hubona \& Ray 2016) (Table 1). The AVE indicates the overall variance in variable items accounted for by the latent constructs. The AVE for all measures except convenience value exceeded the level of 0.5 (Hair et al 2011); however, values lower than that have been previously accepted in behavioral and social sciences studies (Floyd $\&$ Widaman, 1995). These findings confirm the convergent validity of all the proposed indicators.

Discriminant Validity is measured as the extent to which the items are unrelated. It is examined by indicating low correlation between the measurement items different constructs (Cheung \& Lee, 2010). In the proposed measurement model, discriminant validity is confirmed by the Fornell-Larcker criterion according to which the AVE of each variable should be higher than the squared correlations between all other variables (Table 2). Additionally, the heterotrait-monotrait ratios (HTMT) are significantly smaller than 1 (Table 3). As shown in Table 2 and Table 3, the measurement model represents sufficient discriminant validity.

\subsection{Results of the Structural Model and Hypotheses Testing}

The model fit criterion for PLS path modeling is indicated by standardized root mean square residual (SRMR). The SRMR of the model was 0.076 , below the cutoff value of 0.08 suggested by Hensler et al. (2016). The hypothesized paths were analyzed on the basis of significance levels of the path coefficients, after running the bootstrapping procedure set at 4999 samples. The bootstrapping results 
Table 2. Discriminant Validity

\begin{tabular}{|c|c|c|c|c|c|c|c|c|c|c|}
\hline & $\mathbf{A U}$ & ATT & CON & $\mathrm{CV}$ & ENGA & EV & $\mathbf{F E}$ & MV & PBC & SN \\
\hline $\mathrm{AU}$ & 1 & & & & & & & & & \\
\hline ATT & 0.443 & 0.794 & & & & & & & & \\
\hline $\mathrm{CON}$ & 0.155 & 0.492 & 0.716 & & & & & & & \\
\hline $\mathrm{CV}$ & 0.05 & 0.426 & 0.488 & 0.687 & & & & & & \\
\hline ENGA & 0.171 & 0.418 & 0.365 & 0.411 & 0.814 & & & & & \\
\hline EV & 0.191 & 0.491 & 0.616 & 0.555 & 0.431 & 0.738 & & & & \\
\hline FE & 0.129 & 0.262 & 0.367 & 0.324 & 0.741 & 0.445 & 0.715 & & & \\
\hline MV & 0.165 & 0.336 & 0.277 & 0.317 & 0.223 & 0.322 & 0.136 & 0.849 & & \\
\hline PBC & 0.599 & 0.402 & 0.164 & 0.192 & 0.214 & 0.321 & 0.069 & 0.29 & 0.748 & \\
\hline SN & 0.282 & 0.509 & 0.476 & 0.314 & 0.409 & 0.426 & 0.31 & 0.402 & 0.284 & 0.713 \\
\hline
\end{tabular}

are summarized in Table 4. The results indicated seven out of the ten hypothesized relationships are supported. The strongest predictor of actual usage was perceived behavioral control $\left(\beta_{\mathrm{H} 9}=0.503, \mathrm{t}=\right.$ $7.9, p<0.001)$ followed by attitude $\left(\beta_{\mathrm{H} 7}=0.224, \mathrm{t}=3.05, p=0.02\right)$. Flow experience and subjective norms were not found to have any significant influence on actual usage of ESA. Engagement $\left(\beta_{\mathrm{H} 3}=\right.$ $0.215, \mathrm{t}=2.148, p=0.032)$, content $\left(\beta_{\mathrm{H} 4}=0.301, \mathrm{t}=2.881, p=0.004\right)$ and monetary value $\left(\beta_{\mathrm{H} 6}=\right.$ $0.16, \mathrm{t}=2.002, p=0.045)$ significantly predicted attitude towards ESA, whereas convenience value did not. Flow experience very strongly predicted engagement $\left(\beta_{\mathrm{Hla}}=0.741, \mathrm{t}=13.122, p<0.001\right)$ and entertainment value significantly led to flow experience $\left(\beta_{\mathrm{H} 2}=0.445, \mathrm{t}=6.216, p<0.001\right)$.

Table 3. HTMT Ratios

\begin{tabular}{|l|l|l|l|l|l|l|l|l|l|}
\hline & ATT & \multicolumn{1}{|c|}{ CON } & CV & ENGA & EV & FE & MV & PBC & SN \\
\hline ATT & 0.444 & & & & & & & & \\
\hline CON & 0.147 & 0.475 & & & & & & & \\
\hline CV & 0.049 & 0.417 & 0.474 & & & & & & \\
\hline ENGA & 0.17 & 0.417 & 0.361 & 0.412 & & & & & \\
\hline EV & 0.193 & 0.489 & 0.618 & 0.553 & 0.435 & & & & \\
\hline FE & 0.129 & 0.258 & 0.372 & 0.322 & 0.739 & 0.449 & & & \\
\hline MV & 0.166 & 0.334 & 0.258 & 0.315 & 0.223 & 0.332 & 0.13 & & \\
\hline PBC & 0.601 & 0.398 & 0.157 & 0.192 & 0.212 & 0.321 & 0.096 & 0.293 & \\
\hline SN & 0.284 & 0.512 & 0.473 & 0.314 & 0.406 & 0.43 & 0.297 & 0.41 & 0.283 \\
\hline
\end{tabular}

ATT: Atitude, CON: Content, CV: Convenience Value, ENGA: Engagement, EV: Entertainment Value, FE: Flow Experience, MV: Monetary Value, PBC: Perceived Behavioral Control, SN: Subjective Norms, 
Table 4. Path Coefficients

\begin{tabular}{|c|c|c|c|c|c|c|c|}
\hline & & $\begin{array}{c}\text { Path } \\
\text { Coefficients }\end{array}$ & Sample Mean & STDEV & T -values & P- Values & $\begin{array}{l}\text { Hypothesis } \\
\text { Supported }\end{array}$ \\
\hline $\mathrm{H} 1 \mathrm{a}$ & $\mathrm{FE} ® \mathrm{ENGA}$ & 0.741 & 0.739 & 0.056 & 13.122 & 0.000 & Yes \\
\hline $\mathrm{H} 1 \mathrm{~b}$ & $\mathrm{FE} \circledast \mathrm{AU}$ & 0.03 & 0.03 & 0.058 & 0.518 & 0.605 & No \\
\hline $\mathrm{H} 2$ & $\mathrm{EV} ® \mathrm{FE}$ & 0.445 & 0.444 & 0.072 & 6.216 & 0.000 & Yes \\
\hline $\mathrm{H} 3$ & ENGA ${ }^{\circledR}$ ATT & 0.215 & 0.215 & 0.1 & 2.148 & 0.032 & Yes \\
\hline $\mathrm{H} 4$ & $\mathrm{CON} ® \mathrm{ATT}$ & 0.301 & 0.31 & 0.104 & 2.881 & 0.004 & Yes \\
\hline H5 & $\mathrm{CV} ® \mathrm{ATT}$ & 0.14 & 0.142 & 0.099 & 1.417 & 0.157 & No \\
\hline H6 & MV $®$ ATT & 0.16 & 0.157 & 0.08 & 2.002 & 0.045 & Yes \\
\hline $\mathrm{H} 7$ & ATT $® \mathrm{AU}$ & 0.224 & 0.227 & 0.074 & 3.05 & 0.002 & Yes \\
\hline $\mathrm{H} 8$ & $\mathrm{SN} \circledast \mathrm{AU}$ & 0.016 & 0.013 & 0.07 & 0.225 & 0.822 & No \\
\hline $\mathrm{H} 9$ & PBC ®AU & 0.503 & 0.502 & 0.064 & 7.9 & 0.000 & Yes \\
\hline
\end{tabular}

\section{DISCUSSION AND IMPLICATIONS}

The current study conceptualizes and empirically tests a theoretical framework that explains the actual usage of ESA subscriber. The study examined the impact of flow theory in relation with entertainment streaming apps. The results suggest that entertainment value leads to flow experience which in turn leads to engagement. There is however no significant relationship between flow experience and actual usage of ESA. These findings are consistent with those of Chen and Lin (2018) who ascertained that watching live stream might not generate flow since usually, people multitask while watching live stream. This rationale might also be valid for the current study. Flow experience has been widely studied in the context of online games, although using ESA might not require the same concentration or level of engagement as is required for playing video games, since one might get distracted while watching ESA.

The proposed framework validated the effect of entertainment consumption factors such as content, monetary value and engagement on attitude towards ESAs. This finding reinforces the "content-is-king" assertion. Impact of monetary value on attitude aligns with the price sensitive Indian consumer's decision making.

Although, convenience and any time availability of the content is one of the important aspects of using ESA, convenience value was found to have no influence on attitude towards using ESA. It is worth noticing that with increased smartphone and internet penetration, access to digital content is no longer difficult. Entertainment is readily available through multiple channels and sources. Many apps provide options to download and watch the content offline as well. Therefore, convenience may not be a differentiating factor when it comes to availability of digital content.

Attitude was found to have significant influence on actual usage of ESA, but it was perceived behavioral control that has the strongest influence on ESA usage. This emphasizes the role of selfefficacy and individuals' perception of their ability to be able to use ESA without hassle in facilitating its usage. Subjective norms do not affect ESA usage. Many prior studies on technology adoption have supported the role of subjective norms in adoption intentions. But when it comes to actual usage in the context of ESA viewing, normative influences might not be that strong. There could be multiple other factors in play over here such as availability of time, individual's own intrinsic motivations, platform characteristics (interactivity and hedonic value for instance) and personality characteristics or so on. 
Overall, the proposed model provides a comprehensive understanding of what drives actual ESA usage among Indian consumers. This could provide managers a starting point to understand the predictors of ESA usage and help them come up with well-designed content to enhance the entertainment value of ESA and help the audience develop positive attitude towards ESA usage. Additionally, streamers should ensure that the apps are easy to download and install, compatible with most smartphone versions and easy to navigate in order to appeal to the user's perception of self-efficacy in using ESA which is a strong predictor of its usage.

\subsection{Managerial Implications}

The findings yield some pertinent implications for managers or ESA content developers. Based on the findings of the study, it will be advisable for managers to stress on aligning the needs of the audience with the content available on ESA. Major players including Netflix and Amazon Prime have started to focus on locally produced content and customize it as per the viewing preferences of the local audience. ESA players should study the specificities of the market, and cater to their choices both in terms of quality and volume of content. This can also help ESA players to penetrate beyond metro cities in India.

Quality content with focus on enhancing user experience can be the key differentiator. Acknowledging that, ESA platforms can deploy AI based systems to provide differential service and improve user experience. For instance, some platforms provide option of "skip intro" or automatically starting the next episode in serialized content. These features can improve engagement which can lead to a favorable attitude towards ESAs.

Other than identifying viewers' changing preferences of entertainment consumption, it is equally crucial to keep in mind their price sensitive nature and the monetary value of the content being delivered to the audience. Currently, ESA users are required to subscribe to each platform separately which increases the individual cost of accessing the content. As per report by Boston Consulting Group, $82 \%$ of Indian users engage on advertising-led VOD platforms, while only $18 \%$ of the users pay for content on subscription based services (Entertainment Goes Online, 2018). The competitive landscape within ESA is also changing in India with local players posing challenge for major brands. Channels like YouTube and many other regional and local streaming apps including SonyLIV, Zee5 are advertising based model that enable them to offer free content to its viewers. This is significantly affecting subscriber loyalty, since with so many alternatives, it has become common for subscribers to be fickle and they switch their subscription to different platforms whenever they find the content exciting. Therefore, to add members of lower price tier, ESA players should customize their subscription plans to fit consumers' pockets. Netflix, for instance, recently started its mobileonly subscription plan which costs half of its original subscription rate. Similarly, coming up with content based subscription plan, partnering with telecom operators, smartphone brands and bundling the services with subscriptions can help create more value for the user.

\subsection{Theoretical Contribution}

The study contributes to the emerging domain of OTT platforms, VOD and specifically provides implications for subscription based ESAs. Past academic research in this domain has predominantly focused on live stream viewership or on diverse application of streaming services. The current study explores the user behavior in a narrow context of video streaming platforms. It discerned the factors affecting attitude towards ESAs and validated the use of TPB in explaining actual usage of ESA. The proposed model integrates the factors of TPB with factors that apply to psychological needs, such as, flow, entertainment value and engagement. The study also contributes to perceived value literature and validates the results of prior research on perceived value and influence of cognitive efforts (Collier et al., 2014; Oyedele and Simpson, 2018) on consumer decision making. Overall, the theoretical model includes psychological (Flow, engagement), social (subjective norms), individual 
(perceived control) and platform related factors (content, entertainment, convenience and monetary value) thus providing a comprehensive understanding of factors influencing ESA usage.

\section{LIMITATION AND FUTURE STUDIES}

The authors acknowledge that the context of the research and data collection process may limit the generalizability of its results. The data is collected among Indian ESA users. Future research shall replicate the study for other samples to strengthen the findings of the study. There is a scope to examine ESA usage based on different types of content available on these apps (eg: movies, music, seasons or documentaries) and draw a more detailed comparison explaining the effect of content type on usage. Individual characteristics such as personality type, age and gender may also be studied as moderators for ESA usage. Regarding the proposed framework, it is suggested that future studies explore the broadcasters' characteristics in determining ESA usage. A very up and coming areas for research with respect to ESA is the rise of addictive behaviors among young adults caused due to binge watching, which calls for attention from academics and industry alike.

Finally, some platforms have started to integrate gamified elements in their interface. Netflix's popular episode of Black Mirror named Bandersnatch used a choice based narrative and received a lot of attention. In 2018, Hotstar introduced an immersive game experience through Watch 'N Play, for VIVO IPL (the most awaited Indian Cricket League tournament). The game enabled fans to compete with their friends and family and monitor where they stood through Hotstar's social leaderboard. Future research must pay attention to the effect of gamified elements in OTT platforms on viewers' engagement and flow experience and loyalty. 


\section{REFERENCES}

Ajzen, I. (1991). The theory of planned behavior, organizational behavior and human decision processes (Vol. 50). Cited in Hansen.

Ajzen, I. (2002). Perceived behavioral control, self-efficacy, locus of control, and the theory of planned behavior 1. Journal of Applied Social Psychology, 32(4), 665-683. doi:10.1111/j.1559-1816.2002.tb00236.x

Ajzen, I., \& Fishbein, M. (1988). Theory of reasoned action-Theory of planned behavior. University of South Florida, 2007, 67-98.

Alzahrani, A. I., Mahmud, I., Ramayah, T., Alfarraj, O., \& Alalwan, N. (2017). Extending the theory of planned behavior (TPB) to explain online game playing among Malaysian undergraduate students. Telematics and Informatics, 34(4), 239-251. doi:10.1016/j.tele.2016.07.001

Arı, E., Yılmaz, V., \& Dikec, B. E. (2020). An extensive structural model proposal to explain online gaming behaviors. Entertainment Computing, 34, 100340. doi:10.1016/j.entcom.2020.100340

Bardzell, J., Bardzell, S., Pace, T., \& Karnell, J. (2008, April). Making user engagement visible: a multimodal strategy for interactive media experience research. In CHI'08 extended abstracts on Human factors in computing systems (pp. 3663-3668). ACM. doi:10.1145/1358628.1358909

Bellman, S., Potter, R. F., Treleaven-Hassard, S., Robinson, J. A., \& Varan, D. (2011). The effectiveness of branded mobile phone apps. Journal of Interactive Marketing, 25(4), 191-200. doi:10.1016/j.intmar.2011.06.001

Bolduc, H., \& Kinnally, W. (2018). Examining the impact of social identification with music on music streaming behavior. Journal of Radio \& Audio Media, 25(1), 42-61. doi:10.1080/19376529.2017.1362893

Bury, R., \& Li, J. (2013). Is it live or is it timeshifted, streamed or downloaded? Watching television in the era of multiple screens. New Media \& Society, 6(0), 119.

Calder, B. J., \& Malthouse, E. C. (2008). Media engagement and advertising effectiveness. Kellogg on advertising and media, 1-36.

Chang, I. C., Liu, C. C., \& Chen, K. (2014). The effects of hedonic/utilitarian expectations and social influence on continuance intention to play online games. Internet Research, 24(1), 21-45. doi:10.1108/IntR-02-2012-0025

Chen, C. C., \& Lin, Y. C. (2018). What drives live-stream usage intention? The perspectives of flow, entertainment, social interaction, and endorsement. Telematics and Informatics, 35(1), 293-303. doi:10.1016/j.tele.2017.12.003

Chen, Y. N. K. (2019). Competitions between OTT TV platforms and traditional television in Taiwan: A Niche analysis. Telecommunications Policy, 43(9), 101793. doi:10.1016/j.telpol.2018.10.006

Cheung, C. M., \& Lee, M. K. (2010). A theoretical model of intentional social action in online social networks. Decision Support Systems, 49(1), 24-30. doi:10.1016/j.dss.2009.12.006

Chiang, H. S., \& Hsiao, K. L. (2015). YouTube stickiness: The needs, personal, and environmental perspective. Internet Research, 25(1), 85-106. doi:10.1108/IntR-11-2013-0236

Collier, J. E., Sherrell, D. L., Babakus, E., \& Horky, A. B. (2014). Understanding the differences of public and private self-service technology. Journal of Services Marketing. Advance online publication. doi:10.1108/ JSM-04-2012-0071

Compeau, D. R., \& Higgins, C. A. (1995). Computer self-efficacy: Development of a measure and initial test. Management Information Systems Quarterly, 19(2), 189-211. doi:10.2307/249688

Csikszentmihalyi, M. (1975). Beyond boredom and anxiety. Jossey-Bass.

De Wulf, K., Schillewaert, N., Muylle, S., \& Rangarajan, D. (2006). The role of pleasure in web site success. Information \& Management, 43(4), 434-446. doi:10.1016/j.im.2005.10.005

Delikan, M. D. (2010). Changing consumption behavior of net generation and the adoption of streaming music services: Extending the technology acceptance model to account for streaming music services (Master's thesis). Retrieved from http://www.diva-portal.org/smash/get/diva2:324142/FULLTEXT01.pdfJun 
Dörr, J., Wagner, T., Benlian, A., \& Hess, T. (2013). Music as a service as an alternative to music piracy? An empirical investigation of the intention to use music streaming services. Business \& Information Systems Engineering, 5(6), 383-396. doi:10.1007/s12599-013-0294-0

Feijóo, C., Maghiros, I., Abadie, F., \& Gómez-Barroso, J. L. (2009). Exploring a heterogeneous and fragmented digital ecosystem: Mobile content. Telematics and Informatics, 26(3), 282-292. doi:10.1016/j.tele.2008.11.009

Fishbein, M., \& Ajzen, I. (1975). Belief, attitude, intention and behavior: An introduction to theory and research. Academic Press.

Floyd, F. J., \& Widaman, K. F. (1995). Factor analysis in the development and refinement of clinical assessment instruments. Psychological Assessment, 7(3), 286-299. doi:10.1037/1040-3590.7.3.286

Ghani, J. A., \& Deshpande, S. P. (1994). Task characteristics and the experience of optimal flow in humanComputer interaction. The Journal of Psychology, 128(4), 381-391. doi:10.1080/00223980.1994.9712742

Gimpel, G. (2015). The future of video platforms: Key questions shaping the TV and video industry. International Journal on Media Management, 17(1), 25-46.

Greenberg, J. M. (2010). From BetaMax to Blockbuster: Video stores and the invention of movies on video. MIT Press.

Ha, I., Yoon, Y., \& Choi, M. (2007). Determinants of adoption of mobile games under mobile broadband wireless access environment. Information \& Management, 44(3), 276-286. doi:10.1016/j.im.2007.01.001

Hair, J. F., Ringle, C. M., \& Sarstedt, M. (2011). PLS-SEM: Indeed a silver bullet. Journal of Marketing Theory and Practice, 19(2), 139-152. doi:10.2753/MTP1069-6679190202

Hanafizadeh, P., Behboudi, M., Koshksaray, A. A., \& Tabar, M. J. S. (2014). Mobile-banking adoption by Iranian bank clients. Telematics and Informatics, 31(1), 62-78. doi:10.1016/j.tele.2012.11.001

Hargittai, E., \& Walejko, G. (2008). The participation divide: Content creation and sharing in the digital age. Information Communication and Society, 11(2), 239-256. doi:10.1080/13691180801946150

Henseler, J., Hubona, G., \& Ray, P. A. (2016). Using PLS path modeling in new technology research: Updated guidelines. Industrial Management \& Data Systems, 116(1), 2-20. doi:10.1108/IMDS-09-2015-0382

Hilvert-Bruce, Z., Neill, J. T., Sjöblom, M., \& Hamari, J. (2018). Social motivations of live-streaming viewer engagement on Twitch. Computers in Human Behavior, 84, 58-67. doi:10.1016/j.chb.2018.02.013

Hoffman, D. L., \& Novak, T. P. (2009). Flow online: Lessons learned and future prospects. Journal of Interactive Marketing, 23(1), 23-34. doi:10.1016/j.intmar.2008.10.003

Högberg, J., Ramberg, M. O., Gustafsson, A., \& Wästlund, E. (2019). Creating brand engagement through instore gamified customer experiences. Journal of Retailing and Consumer Services, 50, 122-130. doi:10.1016/j. jretconser.2019.05.006

Hongyoun Hahn, K., \& Kim, J. (2009). The effect of offline brand trust and perceived internet confidence on online shopping intention in the integrated multi-channel context. International Journal of Retail \& Distribution Management, 37(2), 126-141. doi:10.1108/09590550910934272

Hsu, C. L., Chang, K. C., \& Chen, M. C. (2012). The impact of website quality on customer satisfaction and purchase intention: Perceived playfulness and perceived flow as mediators. IseB, 10(4), 549-570. doi:10.1007/ s10257-011-0181-5

Hsu, C. L., \& Lu, H. P. (2004). Why do people play on-line games? An extended TAM with social influences and flow experience. Information \& Management, 41(7), 853-868. doi:10.1016/j.im.2003.08.014

Hu, M., Zhang, M., \& Wang, Y. (2017). Why do audiences choose to keep watching on live video streaming platforms? An explanation of dual identification framework. Computers in Human Behavior, 75, 594-606. doi:10.1016/j.chb.2017.06.006

Hung, S. Y., Tsai, J. C. A., \& Chou, S. T. (2016). Decomposing perceived playfulness: A contextual examination of two social networking sites. Information \& Management, 53(6), 698-716. doi:10.1016/j.im.2016.02.005 
Indian OTT Platform Report. (2019). New Regional Flavours, More Entertaining Content. MICA, Centre for Media and Entertainment Studies (CMES). https://communicationcrafts.in/wp-content/uploads/2019/12/ Indian_ott_report2019.pdf

Jha, L. (2020). India's online video market to touch $\$ 4$ billion by 2025. Live Mint. https://www.livemint.com/ companies/news/india-s-online-video-market-to-touch-4-billion-by-2025-11589795634495.html

Kaba, B. (2018). Modeling information and communication technology use continuance behavior: Are there differences between users on basis of their status? International Journal of Information Management, 38(1), 77-85. doi:10.1016/j.ijinfomgt.2017.08.007

Kim, D., \& Ko, Y. J. (2019). The impact of virtual reality (VR) technology on sport spectators' flow experience and satisfaction. Computers in Human Behavior, 93, 346-356. doi:10.1016/j.chb.2018.12.040

Kim, H., \& Niehm, L. S. (2009). The impact of website quality on information quality, value, and loyalty intentions in apparel retailing. Journal of Interactive Marketing, 23(3), 221-233. doi:10.1016/j.intmar.2009.04.009

Kim, H. S., \& Kim, M. (2020). Viewing sports online together? Psychological consequences on social live streaming service usage. Sport Management Review, 23(5), 869-882. Advance online publication. doi:10.1016/j. smr.2019.12.007

Kim, K. J., \& Shin, D. H. (2015). An acceptance model for smart watches: Implications for the adoption of future wearable technology. Internet Research, 25(4), 527-541. doi:10.1108/IntR-05-2014-0126

Kim, S., \& Baek, T. H. (2018). Examining the antecedents and consequences of mobile app engagement. Telematics and Informatics, 35(1), 148-158. doi:10.1016/j.tele.2017.10.008

Kim, Y. H., Kim, D. J., \& Wachter, K. (2013). A study of mobile user engagement (MoEN): Engagement motivations, perceived value, satisfaction, and continued engagement intention. Decision Support Systems, 56, 361-370. doi:10.1016/j.dss.2013.07.002

Kinnally, W., \& Bolduc, H. (2020). Integrating the theory of planned behavior and uses and gratifications to understand music streaming intentions and behavior. Atlantic Journal of Communication, 28(3), 1-15. doi:10. $1080 / 15456870.2020 .1718676$

Kinnally, W., \& Brinkerhoff, B. (2013). Improving the drive: A case study for modeling public radio member donations using the theory of planned behavior. Journal of Radio \& Audio Media, 20(1), 2-16. doi:10.1080/1 9376529.2013.777733

Kleijnen, M., De Ruyter, K., \& Wetzels, M. (2007). An assessment of value creation in mobile service delivery and the moderating role of time consciousness. Journal of Retailing, 83(1), 33-46. doi:10.1016/j.jretai.2006.10.004

Kock, N. (2015). Common method bias in PLS-SEM: A full collinearity assessment approach. International Journal of e-Collaboration (IJeC), 11(4), 1-10.

Lai, L. S., \& Turban, E. (2008). Groups formation and operations in the Web 2.0 environment and social networks. Group Decision and Negotiation, 17(5), 387-402. doi:10.1007/s10726-008-9113-2

Liao, C., Chen, J. L., \& Yen, D. C. (2007). Theory of planning behavior (TPB) and customer satisfaction in the continued use of e-service: An integrated model. Computers in Human Behavior, 23(6), $2804-2822$. doi:10.1016/j.chb.2006.05.006

Lin, T., Hsu, J. S., \& Chen, H. (2013). Customer willingness to pay for online music: The role of free mentality. Journal of Electronic Commerce Research, 14(4), 315-333.

Liu, C. C. (2017). A model for exploring players flow experience in online games. Information Technology \& People, 30(1), 139-162. doi:10.1108/ITP-06-2015-0139

Loureiro, M. C. S., Rüdiger Kaufmann, H., \& Rabino, S. (2014). Intentions to use and recommend to others: An empirical study of online banking practices in Portugal and Austria. Online Information Review, 38(2), 186-208. doi:10.1108/OIR-01-2012-0100

Lu, Y., Zhou, T., \& Wang, B. (2009). Exploring Chinese users' acceptance of instant messaging using the theory of planned behavior, the technology acceptance model, and the flow theory. Computers in Human Behavior, 25(1), 29-39. doi:10.1016/j.chb.2008.06.002 
Luo, H., Ma, L., Lin, X., \& Gan, X. (2011, June). Longitudinal research on consumers' trust in B2C E-business. In ICSSSM11 (pp. 1-6). IEEE. doi:10.1109/ICSSSM.2011.5959529

Madupu, V., \& Cooley, D. O. (2010). Antecedents and consequences of online brand community participation: A conceptual framework. Journal of Internet Commerce, 9(2), 127-147. doi:10.1080/15332861.2010.503850

Mäntymäki, M., Merikivi, J., Verhagen, T., Feldberg, F., \& Rajala, R. (2014). Does a contextualized theory of planned behavior explain why teenagers stay in virtual worlds? International Journal of Information Management, 34(5), 567-576. doi:10.1016/j.ijinfomgt.2014.05.003

Market Analysis Report. (2020). Video Streaming Market Size, Share \& Trends Analysis Report. Grand View Research. https://www.grandviewresearch.com/industry-analysis/video-streaming-market

McQuail, D. (2010). Mass Communication Theory: An Introduction. SAGE.

Medina, M., Herrero-Subías, M., \& Guerrero, E. (2015, June). Audience behaviour and multiplatform strategies: The path towards connected TV in Spain. Austral Comunicación, 4(1), 153-172. doi:10.26422/aucom.2015.0401. med

Merikivi, J., Bragge, J., Scornavacca, E., \& Verhagen, T. (2020). Binge-watching serialized video content: A transdisciplinary review. Television \& New Media, 21(7), 697-711. doi:10.1177/1527476419848578

Mohd-Any, A. A., Winklhofer, H., \& Ennew, C. (2015). Measuring users' value experience on a travel website (e-value) what value is cocreated by the user? Journal of Travel Research, 54(4), 496-510. doi:10.1177/0047287514522879

Mollen, A., \& Wilson, H. (2010). Engagement, telepresence and interactivity in online consumer experience: Reconciling scholastic and managerial perspectives. Journal of Business Research, 63(9-10), 919-925. doi:10.1016/j.jbusres.2009.05.014

Naidu, R., \& Laghate, G. (2020). Understanding India's streaming platforms industry in the context of lockdown. The Economic Times. https://economictimes.indiatimes.com/industry/media/entertainment/understanding-indiasstreaming-platforms-industry-in-the-context-of-lockdown/articleshow $/ 75840538 . \mathrm{cms}$ ?from $=\mathrm{mdr}$

Oyedele, A., \& Simpson, P. M. (2018). Streaming apps: What consumers value. Journal of Retailing and Consumer Services, 41, 296-304. doi:10.1016/j.jretconser.2017.04.006

Pihlström, M., \& Brush, G. J. (2008). Comparing the perceived value of information and entertainment mobile services. Psychology and Marketing, 25(8), 732-755. doi:10.1002/mar.20236

Pura, M. (2005). Linking perceived value and loyalty in location-based mobile services. Managing Service Quality, 15(6), 509-538. doi:10.1108/09604520510634005

Rogatko, T. P. (2009). The influence of flow on positive affect in college students. Journal of Happiness Studies, 10(2), 133-148. doi:10.1007/s10902-007-9069-y

Sanjamsai, S., \& Phukao, D. (2018). Flow experience in computer game playing among Thai university students. Kasetsart Journal of Social Sciences, 39(2), 175-182. doi:10.1016/j.kjss.2018.03.003

Simons, H. W. (1976). Persuasion: Understanding, practice, and analysis. Addison Wesley Publishing Company.

Sjöblom, M., \& Hamari, J. (2017). Why do people watch others play video games? An empirical study on the motivations of Twitch users. Computers in Human Behavior, 75, 985-996. doi:10.1016/j.chb.2016.10.019

Steinkamp, C. (2010). Internet television use: Motivations and preferences for watching television online among college students (Master's thesis). https://scholarworks.rit.edu/theses/4525/

Su, Y. S., Chiang, W. L., Lee, C. T. J., \& Chang, H. C. (2016). The effect of flow experience on player loyalty in mobile game application. Computers in Human Behavior, 63, 240-248. doi:10.1016/j.chb.2016.05.049

Sundar, S. S. (2012). Social psychology of interactivity in human-website interaction. In Oxford handbook of internet psychology. Oxford University Press.

Sundaravel, E., \& Elangovan, N. (n.d.). Emergence and future of Over-the-top (OTT) video services in India: an analytical research. International Journal of Business, Management and Social Research, 8(2), 489-499. 
The Quint. (2018, July 16). Success of 'Sacred Games' Means Netflix Is Here to Stay - But How? Retrieved from: https://www.thequint.com/entertainment/netflix-makes-mark-on-india

The Quint. (2019, June 12). India Has World's Second-Largest Internet User Base. Retrieved from: https://www. bloombergquint.com/technology/india-has-worlds-second-largest-internet-user-base

Tseng, T. H., Huang, H. H., \& Setiawan, A. (2017). How do motivations for commitment in online brand communities evolve? The distinction between knowledge-and entertainment-seeking motivations. Computers in Human Behavior, 77, 326-335. doi:10.1016/j.chb.2017.09.016

Venkatesh, V., Thong, J. Y., \& Xu, X. (2012). Consumer acceptance and use of information technology: Extending the unified theory of acceptance and use of technology. Management Information Systems Quarterly, 36(1), 157-178. doi: $10.2307 / 41410412$

$\mathrm{Wu}, \mathrm{L}$. (2016). Understanding the impact of media engagement on the perceived value and acceptance of advertising within mobile social networks. Journal of Interactive Advertising, 16(1), 59-73. doi:10.1080/152 52019.2016.1160331

Yang, H. C. (2013). Bon Appétit for apps: Young American consumers' acceptance of mobile applications. Journal of Computer Information Systems, 53(3), 85-96. doi:10.1080/08874417.2013.11645635

Yang, K. (2012). Consumer technology traits in determining mobile shopping adoption: An application of the extended theory of planned behavior. Journal of Retailing and Consumer Services, 19(5), 484-491. doi:10.1016/j. jretconser.2012.06.003

Zaman, M., Anandarajan, M., \& Dai, Q. (2010). Experiencing flow with instant messaging and its facilitating role on creative behaviors. Computers in Human Behavior, 26(5), 1009-1018. doi:10.1016/j.chb.2010.03.001

Zhao, Z., \& Balagué, C. (2015). Designing branded mobile apps: Fundamentals and recommendations. Business Horizons, 58(3), 305-315. doi:10.1016/j.bushor.2015.01.004

Zhou, T., \& Lu, Y. (2011). Examining mobile instant messaging user loyalty from the perspectives of network externalities and flow experience. Computers in Human Behavior, 27(2), 883-889. doi:10.1016/j.chb.2010.11.013 


\section{ENDNOTE}

Abbreviations used: OTT: Over the top; VOD: Video on Demand; ESA: Entertainment Streaming Apps, TPB: Theory of Planned Behavior; IS: Information System; PBC: Perceived Behavioral Control; ICT: Information and Communication Technology; VIF: Variance Inflation Factors; AVE: Average Variance Explained; CR: Composite Reliability; SRMR: Standardized Root Mean Square Residual 


\section{APPENDIX}

\begin{tabular}{|c|c|c|}
\hline Items & $\begin{array}{l}\text { Factor } \\
\text { Loadings }\end{array}$ & Reference` \\
\hline \multicolumn{2}{|l|}{ Attitude $(\mathrm{AVE}=0.63, \alpha=0.895, \mathrm{CR}=0.894)$} & \multirow{7}{*}{ Ajzen (2002) } \\
\hline \multicolumn{2}{|l|}{ Select the option that best represents how you feel about using ESAs } & \\
\hline Good ------ Bad & 0.915 & \\
\hline Harmful------- Beneficial & 0.823 & \\
\hline Unpleasant ---------- Pleasant & 0.74 & \\
\hline Un-enjoyable ---------- Enjoyable & 0.776 & \\
\hline Foolish -.----- Wise & 0.698 & \\
\hline \multicolumn{2}{|l|}{ Convenience Value $(\mathrm{AVE}=0.472, \alpha=0.82, \mathrm{CR}=0.817)$} & \multirow{6}{*}{$\begin{array}{l}\text { Collier et al. } \\
\quad(2013\end{array}$} \\
\hline ESAs allow me to watch or listen to whatever I want whenever I choose. & 0.745 & \\
\hline ESAs allow me to watch or listen to whatever I want at a convenient time & 0.667 & \\
\hline I value the ability to use ESAs to watch or listen to what I want while away from home & 0.708 & \\
\hline I like the ability to use ESAs to watch or listen to what I want on multiple devices (e.g., iPads, smartphones) & 0.697 & \\
\hline I like the ability to use ESAs to watch or listen to what I want from anywhere & 0.611 & \\
\hline \multicolumn{2}{|l|}{ Content $(\mathrm{AVE}=0.513, \alpha=0.755, \mathrm{CR}=0.752)$} & \multirow{4}{*}{$\begin{array}{l}\text { De Wulf et al. } \\
\text { (2006) }\end{array}$} \\
\hline The content offered and available is up-to-date & 0.506 & \\
\hline The content offered is diverse and sufficient & 0.807 & \\
\hline The content offered allows me to get informed & 0.794 & \\
\hline \multicolumn{2}{|l|}{ Engagement $(\mathrm{AVE}=0.663, \alpha=0.855, \mathrm{CR}=0.855)$} & \multirow{4}{*}{$\begin{array}{c}\text { Ghani and } \\
\text { Deshpande } \\
\text { (1994); Koufaris } \\
(2002\end{array}$} \\
\hline When using ESAs, I am usually absorbed intensely in the activity & 0.798 & \\
\hline When using ESAs, I concentrate fully on the activity & 0.779 & \\
\hline While during using ESAs, I am deeply engrossed in the activity & 0.864 & \\
\hline \multicolumn{2}{|l|}{ Entertainment Value $(\mathrm{AVE}=0.545, \alpha=0.815, \mathrm{CR}=0.824)$} & \multirow{5}{*}{$\begin{array}{l}\text { Venkatesh et al., } \\
\text { 2012; Kim et al., } \\
2005\end{array}$} \\
\hline ESAs are very entertaining & 0.774 & \\
\hline ESAs are fun & 0.663 & \\
\hline ESAs are enjoyable & 0.881 & \\
\hline ESAs are a leisure activity & 0.602 & \\
\hline \multicolumn{2}{|l|}{ Flow Experience $(\mathrm{AVE}=0.511, \alpha=0.81, \mathrm{CR}=0.806)$} & \multirow{6}{*}{$\begin{array}{l}\text { Lu et al., } 2009 \\
\text { and Huang, } 2003\end{array}$} \\
\hline When using ESAs, I do not realize the time elapsed. & 0.666 & \\
\hline When using ESAs, I am not aware of things happening around me. & 0.708 & \\
\hline When using ESAs, I often forget the work I must do. & 0.663 & \\
\hline Using ESAs excited my curiosity. & 0.812 & \\
\hline Using ESAs aroused my imagination. & 0.863 & \\
\hline \multicolumn{2}{|l|}{ Monetary Value $(\mathrm{AVE}=0.721, \alpha=0.887, \mathrm{CR}=0.885)$} & \multirow{4}{*}{$\begin{array}{l}\text { Mohd-Any et al. } \\
\qquad(2015)\end{array}$} \\
\hline $\begin{array}{l}\text { I feel that the subscription cost of ESAs is not expensive relative to substitute services such as buying or renting DVDs and } \\
C D s\end{array}$ & 0.863 & \\
\hline I feel that using ESAs offer significant cost savings relative to substitute services such as buying or renting DVDs and CDs & 0.783 & \\
\hline I feel that using ESAs is cost effective relative to buying or renting DVDs and CDs. & 0.897 & \\
\hline
\end{tabular}




\begin{tabular}{|c|c|c|}
\hline Items & $\begin{array}{c}\text { Factor } \\
\text { Loadings }\end{array}$ & Reference` \\
\hline \multicolumn{2}{|l|}{ Perceived Behavioral Control $(\mathrm{AVE}=0.56, \alpha=0.835, \mathrm{CR}=0.835)$} & \multirow{5}{*}{$\begin{array}{l}\text { Ajzen, 1991; } \\
\text { Taylor and Todd, } \\
\text { 1995a) }\end{array}$} \\
\hline I have the resources, knowledge, and ability to use ESAs & 0.732 & \\
\hline I can use ESAs & 0.802 & \\
\hline I know how to use ESAs, & 0.677 & \\
\hline Using ESAs is entirely within my control. & 0.777 & \\
\hline \multicolumn{2}{|l|}{ Subjective Norms (AVE $=0.508, \alpha=0.752, C R=0.755)$} & \multirow{4}{*}{ Ajzen, 1991} \\
\hline People who influence my behavior would think that I should use ESAs & 0.728 & \\
\hline People who are important to me would think I should use ESAs & 0.756 & \\
\hline My family who are important to me would think that using ESAs is a good idea. & 0.65 & \\
\hline
\end{tabular}

Vishal Kulshrestha is pursuing PhD at Amity International Business School from Amity University, Noida and is an Assistant Professor at IIMT University. His research interest area is Consumer Behavior. An NMIMS alumnus, he has over 8 years of teaching experience, backed by strong industry exposure.

Kokil Jain is a Professor and Area Chairperson, Marketing at Amity International Business School, Amity University Noida, UP, India. She is a Doctorate in Management with over 16 years of experience in the area of teaching and research. She has keen interest and expertise in the area of Brand Management and Consumer Behaviour. She has published research articles in Journals of repute. Her present areas of research include Luxury Branding, Brand Anthropomorphism and Online Consumer Brand Relationships.

Isha Sharma is an Assistant Professor, Marketing at School of Administrative Studies, York University, Toronto, Canada. Her research focuses on studying consumer behavior pertaining to emerging technologies, exploring the application of $A$ I in marketing, gamification in marketing, brand identity, consumer brand relationships, online consumer culture, and services transgression She holds expertise in both qualitative and quantitative research methods and has published research articles in reputed journals. 